\title{
Panorama brasileiro do ensino de Enfermagem On-line
}

\author{
APANORAMA OF BRAZIL'S ONLINE NURSING TEACHING
}

PANORAMA BRASILEÑO DE LA ENSEÑANZA DE ENFERMERÍA VÍA ON-LINE

\author{
Rita de Cassia Vieira Rodrigues ${ }^{1}$, Heloisa Helena Ciqueto Peres²
}

\section{RESUMO}

$\mathrm{O}$ objetivo deste estudo foi identificar os cursos de Ensino Superior Nacional de EAD por área de concentração, região geográfica, nível de formação e os cursos de EAD no ensino superior de Enfermagem. 0 método adotado foi um estudo exploratório descritivo em que foi realizado um levantamento nos sites e portais governamentais e não-governamentais relacionados à educação nacional e EAD das Instituições de Ensino Superior (IES) que praticam EAD. Nos resultados foram identificados apenas dois cursos de pósgraduação lato sensu oferecidos especificamente em Enfermagem. Assim, há necessidade de maior investimento das IES de Enfermagem na criação e avaliação de cursos de EAD, bem como de infra-estrutura e de implementação de uma política de capacitação tecnológica.

\section{DESCRITORES}

Educação em enfermagem.

Educação a distância.

Tecnologia educacional.

\begin{abstract}
The aim of this study was to identify the National Superior Teaching courses in distance education by concentration area, geographic region, graduation level and distance education Nursing courses in higher education. The method used was an exploratory descriptive study in which was carried out a survey in government and nongovernment sites and portals related to national and distance education of higher education schools that offer distance education. The results identified only two latu sensu Graduate courses that offer Nursing specifically. Thus Nursing higher education schools must invest more on creating and evaluating distance education courses, as well as on infra-structure and on the implementation of a policy of technological capacity-building.
\end{abstract}

\section{KEYWORDS}

Education, nursing.

Education, distance.

Educational technology.

\section{RESUMEN}

El objetivo de este estudio fue identificar los cursos de Enseñanza Superior Nacional de la Educación a Distancia (EAD) por área de concentración, región geográfica, nivel de formación y los cursos de EAD en la enseñanza superior de Enfermería. El método adoptado fue un estudio exploratorio descriptivo en el que se llevó a cabo un levantamiento en los sitios y páginas web gubernamentales y no gubernamentales relacionados a la educación nacional y a la EAD de las Instituciones de Enseñanza Superior (IES) que practican EAD. En los resultados fueron identificados apenas dos cursos de post-grado lato sensu ofrecidos específicamente en Enfermería. De este modo, hay necesidad de mayor inversión de las IES de Enfermería en la creación y evaluación de cursos de EAD, así como de infraestructura e implementación de una política de capacitación tecnológica.

\section{DESCRIPTORES}

Educación en enfermería.

Educación a distancia.

Tecnología educacional.

${ }^{1}$ Enfermeira. Mestranda em enfermagem, Escola de Enfermagem, Universidade de São Paulo (EEUSP). São Paulo, SP, Brasil. rcassiarodrigues@hotmail.com ${ }^{2}$ Enfermeira. Doutora. Professora do Departamento de Orientação Profissional da EEUSP. São Paulo, SP, Brasil. hhcperes@usp.br 


\section{INTRODUÇÃO}

O surgimento de novas tecnologias da informação e da comunicação (TICS) vem modificando o paradigma do ensino/aprendizagem e das relações entre o indivíduo, o trabalho e a sociedade como hoje os conhecemos. As inovações tecnológicas alcançadas neste século foram de fundamental importância para a concretização do fenômeno da globalização. 0 mundo globalizado exige que o indivíduo se mantenha atualizado de forma permanente e contínua para exercer de forma efetiva e ativa a sua cidadania ${ }^{(1)}$.

A disseminação e valorização das informações e das novas tecnologias de comunicação possuem representatividade acentuada na sociedade pós-moderna, hoje dita sociedade da informação. Governos de países, entidades e organizações promotoras do bem-estar e desenvolvimento social têm se dedicado à criação e implementação de programas de inclusão digital para o cidadão comum.

0 desenvolvimento tecnológico, assim como a disseminação da informação, ocasiona mudanças positivas na sociedade através da reorganização do trabalho, melhoria na produção e, conseqüentemente, na produtividade, além da aquisição de competências pelo indivíduo como: capacidade de trabalhar em equipe, desenvolvimento da criatividade e pensamento crítico, habilidade para tomada de decisões e comunicação ${ }^{(2)}$.

$\mathrm{Na}$ literatura os termos informática, tecnologia da informação e tecnologia da informação e da comunicação têm sido muito difundidos, para melhor compreensão do seu significado e suas implicações, faz-se necessário a definição destes termos. Assim:

- Informática: é a ciência que lida com a criação, apresentação, forma, produção, avaliação, uso e manutenção de sistemas de processamento de informação.

- Tecnologia da informática: é a aplicação tecnológica da informática no âmbito social.

- Tecnologia da informação e da comunicação (TICS): tratase da utilização das tecnologias da informática como veículo para transmissão, disseminação, transformação e criação de conteúdos que podem estar ou não associados a uma metodologia de ensino(2).

Uma das tecnologias da informática que serve como veículo para as TICs é a Internet através da World Wide Web (Web). A Web corresponde à parte multimídia da Internet que permite 0 acesso a textos, som, imagens, vídeos, jogos e animações. Pode ser utilizada com fins comerciais, acadêmicos, científicos, pessoais, profissionais, educativos e de entretenimento. Devido ao fato de oferecer uma multiplicidade de recursos a Web vem sendo utilizada e pesquisada como um importante recurso para a educação ${ }^{(3-4)}$.
Nesta última década tem crescido a utilização das TICS na educação tornando o ensino mais dinâmico e interativo. Dentre as novas tecnologias podemos citar o uso da televisão, vídeo, telefone, fax e computador, entre outras. A educação não pode estar restrita, apenas, aos recursos da sala de aula, aos livros, ao quadro negro e ao giz. Novos parâmetros para o ensino-aprendizagem estão surgindo, modificando a forma de se construir o conhecimento e transformando tanto a metodologia do ensino como o papel do professor e sua relação com os alunos ${ }^{(5)}$.

A apropriação da informática no ensino deve estar fundamentada em novas experiências pedagógicas que questionam os sistemas educacionais tradicionais e a aderência às novas tecno logias como instrumentos potencializadores da aprendizagem libertadora e dialógica, em favor da promoção humana e da cidadania ${ }^{(6)}$.

Nesse contexto observa-se, ainda, a retomada do ensino a distância utilizando as TICs a partir da publicação da nova Lei de Diretrizes e Bases (LDB n` 9.394 de 20 de dezembro de 1996) que fomenta a implantação e o desenvolvimento de cursos utilizando esta metodologia para a graduação, cursos de extensão, seqüenciais, pós-graduação, educação de jovens e adultos, aperfeiçoamento de professores e educação continuada. Este movimento vem se intensificando também a partir de 1998, quando o Ministério da Educação e Cultura (MEC) começou a cadastrar instituições de ensino superior para oferecimento de cursos a distância utilizando vários tipos de mídia, como CD-ROM, videoconferência, Internet e outros ${ }^{(7)}$.

A educação a distância é o processo de ensino-aprendizagem no qual professor e aluno não se encontram presentes fisicamente na mesma hora e no mesmo espaço geográfico. Dentro deste conceito a EAD pode ser realizada utilizando-se várias mídias ou instrumentos, evoluindo ao longo do tempo da mídia impressa até a Internet.

A EAD está presente no Brasil desde 1904 quando teve início o oferecimento de cursos por correspondência, sendo posteriormente praticada através do rádio (1923) e da televisão (1961). Nesta época o principal enfoque desta modalidade de ensino era a veiculação de cursos de alfabetização e profissionalizantes ${ }^{(8)}$.

Atualmente, a EAD on-line possui uma conotação diferente da praticada anteriormente pelo fato de destinarse, principalmente, à formação de adultos em nível de graduação, pós-graduação, extensão, cursos seqüenciais e educação continuada. A EAD através da Internet tem se mostrado adequada e vantajosa como instrumento para processos de ensino-aprendizagem não apenas pela característica de acessibilidade em qualquer tempo e lugar, mas principalmente pela multiplicidade de recursos que oferece, a interatividade e diversidade de estímulos que 
esta modalidade de ensino possibilita, além da oportunidade de integração e de trabalho cooperativo que pode proporcionar ${ }^{(9)}$

A evolução da EAD on-line levou a criação dos ambientes virtuais de aprendizagem ou Learning $M$ anagement Systems (LMS - sistemas de gerenciamento de aprendizagem), que são ambientes propícios ao desenvolvimento de atividades pedagógicas. Podemos citar como exemplos de LM So TelEduc, M OODLE, Blackboard, AulaNet e o WebCT entre outros. Estes ambientes disponibilizam ao usuário, professor e aluno, vários recursos que podem ser utilizados como estratégias de ensino. Fazem parte destes recursos o chat, o fórum, email, listas de discussão, blogs e teleconferência ${ }^{(10-11)}$.

0 interesse das Instituições de Ensino Superior (IES) pela EAD no Brasil cresceu após a LDB de 1996 que iniciou a regulamentação de cursos a distância e também per-mitiu 0 oferecimento de até $20 \%$ da carga horária de cursos presenciais já regulamentados pelo sistema a distância. Em 2005 o investimento governamental na EAD culminou com a criação da Universidade Aberta do Brasil (UAB), que constitui um consórcio de universidades públicas e centros tecnológicos para oferecimento de cursos a distância ${ }^{(7,12)}$.

$\mathrm{Na}$ área da saúde o uso da Internet na busca de fontes de informação, realização de pesquisas, acesso à base de dados de artigos, teses e periódicos, uso de programas de simulação para treinamento de habilidades e tomada de decisões se constituem objeto de estudos e interesse. A oportunidade de utilizar a Web e obter meios de aperfeiçoamento profissional constante e de qualidade através do acesso a sites de universidades e revistas científicas, além de poder entrar em contato com outros profissionais para troca de informações e da realização de cursos a distância, se tornou condição fundamental para capacitação de pessoal.

$\mathrm{Na}$ enfermagem brasileira observa-se 0 crescimento da produção científica nessa área com tendência em desenvolver ambientes virtuais de aprendizagem a partir de pesquisas de mestrado e doutorado, com predomínio na formação e na capacitação dos enfermeiros na área assistencial e na educação à saúde da população(13).

Assim, constata-se a riqueza da Web como um meio precioso para favorecer o crescimento profissional e a gran-de capacidade de disseminar informações a partir dos cursos a distância mediados pela Internet, bem como a importância de desenvolver estudos na área da educação a distância (EAD) através da Internet, como recurso para educação continuada dos profissionais da saúde e de enfermagem.

Diante do exposto este estudo tem a finalidade de realizar um levantamento sobre a inclusão do Ensino de Enfermagem Superior no panorama brasileiro da EAD on-line.

\section{Os objetivos deste estudo são:}

- Identificar os cursos de ensino superior nacional que utilizam EAD por região do Brasil, por tipo de organização jurídica, por nível de formação e por área de concentração (saúde, exatas, humanas);
- Identificar os cursos de ensino superior de enfermagem na modalidade EAD.

\section{MÉTODO}

Este estudo constitui-se uma pesquisa exploratória descritiva, desenvolvida a partir dos sites e portais das Instituições de Ensino Superior (IES) que praticam EAD.

Inicialmente foi realizado um levantamento dos sites governamentais e não governamentais relacionados à educação nacional e à educação à distância, visando obter informação sobre 0 ensino on-line nacionais e em enfermagem e novas tecnologias da informação e comunicação na educação.

Após esta primeira fase, no período de 2005 até julho de 2006, foi realizado o levantamento das Instituições de Ensino Superior (IES) que são cadastradas no M inistério da Educação e Cultura (MEC) para oferecimento de cursos a distância. Para tanto, foram consultados o portal do MEC e os sites do Instituto Nacional de Estudos e Pesquisas Educacionais (Inep) e da Associação Brasileira de Educação a Distância (ABED). Assim, foram acessados os endereços eletrônicos das respectivas instituições para verificação dos cursos e levantamento dos dados ${ }^{(14-16)}$.

Após identificação dos dados registrados nos sites e no portal referentes à temática do estudo foi realizada uma categorização dos dados obtidos em área de concentração, região brasileira e nível de formação, sendo posteriormente analisados à luz do referencial teórico em EAD.

\section{RESULTADOS E DISCUSSÃO}

Os números da EAD vêm crescendo nos últimos anos de forma significativa, mas ainda são pouco expressivos se comparados à educação tradicional(17).

Conforme a tabela 1 , podemos verificar que existem 129 IES que promovem cursos a distância de graduação, pós-graduação (lato sensu), mestrado e extensão.

Tabela 1 - Distribuição das Instituições de Ensino Superiores que oferecem EAD por regiões do Brasil - São Paulo $-2006$

\begin{tabular}{lcc}
\hline \multicolumn{3}{c}{$\begin{array}{c}\text { IES que oferecem EAD } \\
\text { por região do país }\end{array}$} \\
\hline \multicolumn{1}{c}{ Regiões } & $N^{\text {o }}$ & Porcentagem \\
\hline Sudeste & 60 & $46,5 \%$ \\
Sul & 30 & $23,3 \%$ \\
Nordeste & 19 & $14,7 \%$ \\
Centro-oeste & 13 & $10 \%$ \\
Norte & 7 & $5,5 \%$ \\
\hline Total & 129 & $100 \%$ \\
\hline
\end{tabular}


A região sudeste possui a maior concentração de IES que praticam EAD $(46,5 \%)$ no país, sendo a região norte a menos desenvolvida nesta área da educação. Ainda são muito poucas as instituições que se dedicam a esta modalidade educacional no Brasil visto que, em 2005, havia 2.329 IES públicas e privadas cadastradas junto ao MEC. A tendência deste cenário é a expansão, pois segundo 0 anuário publicado pela ABED, houve um crescimento de $30,7 \%$ no número de instituições que solicitaram sua inscrição junto ao Sistema de Ensino para atuarem neste segmento(17).

A tabela 2 nos mostra o número de IES que oferecem EAD classificadas por tipo de organização jurídica. Como podemos observar, $65,1 \%$ das instituições superiores pertencem ao setor privado. Atualmente 0 ensino superior brasileiro encontra-se massivamente nas mãos da iniciativa privada e este é o setor que apresenta os maiores investimentos na incorporação de novas tecnologias da educação. Segundo o Inep, das 2.329 IES registradas junto ao MEC em 2005, 2.093 eram particulares e apenas 236 constituiam instituições públicas.

Tabela 2 - Distribuição das Instituições de Ensino Superior que oferecem EAD por tipo de organização jurídica - São Paulo - 2006

\begin{tabular}{lcc}
\hline \multicolumn{3}{c}{$\begin{array}{c}\text { IES que oferecem EAD por } \\
\text { tipo de organização - Brasil }\end{array}$} \\
\hline \multicolumn{1}{c}{ IES } & $\mathrm{N}^{\circ}$ & Porcentagem \\
Privada & 84 & $65,1 \%$ \\
Pública Federal & 24 & $18,6 \%$ \\
Pública Estadual & 18 & $14 \%$ \\
Pública Municipal & 03 & $2,3 \%$ \\
\hline TOTAL & 129 & $100 \%$ \\
\hline
\end{tabular}

A ABED realizou uma pesquisa junto a todos os estabelecimentos de ensino cadastrados que praticam EAD no ano de 2005 e um dos dados identificados foram os recursos ou tipos de apoio oferecidos aos estudantes durante o curso a distância. Conforme esse estudo os recursos mais oferecidos aos alunos para solução de dúvidas, troca de informações e suporte por parte do professor nestes estabelecimentos foram: e-mail em $86,7 \%$; contato telefônico em 82,7\%; professor on-line em $78,6 \%$ e professor presencial em $70,4 \%$.

Devemos destacar que as instituições de ensino normalmente utilizam mais de um recurso como apoio ao aluno durante os cursos ${ }^{(17)}$.

Um dado significativo observado nesta pesquisa foi o não oferecimento de apoio ao estudante por $1 \%$ de instituições públicas. Isto constitui um fato grave, pois o apoio ao estudante contribui para que este se sinta motivado a aprender, reduz a sua sensação de isolamento e contribui para redução da taxa de abandono do curso ${ }^{(17)}$.

A pesquisa da ABED também salienta que a mídia mais utilizada pelas instituições de ensino durante 0 oferecimento dos cursos a distância é a mídia impressa (83\%). Ainda é massivo o envio de material impresso ou através de CD-ROM aos alunos como complementação ao material disponibilizado através do e-learning. Esta atitude se deve em grande parte à cultura do ensino presencial. A segunda mídia mais utilizada é o e-learning com $60 \%$, seguida pelo CD-ROM com $42 \%(17)$.

Acreditamos que o desenvolvimento da EAD brasileira e a inclusão digital progressiva da população associada à melhoria das conexões da Internet nacional modificarão este quadro onde a distribuição de material impresso será cada vez menor. Um outro fator que contribui para este cenário é a dificuldade de transformar ou adequar 0 conteúdo didático ao ambiente virtual.

A tabela 3 nos mostra a distribuição do nível de formação por região do país em EAD. Podemos observar o predomínio de cursos de pós-graduação sobre os demais. Muitos autores consideram a EAD mais adequada para adultos e voltada para indivíduos que já possuam algum grau de formação educacional. Isto se deve ao fato de exigir que 0 estudante tenha maior responsabilidade para cumprir e gerenciar sua carga horária de estudos desenvolvendo autonomia(9).

Tabela 3 - Distribuição dos cursos na modalidade EAD por nível de formação nas regiões do país - São Paulo - 2006

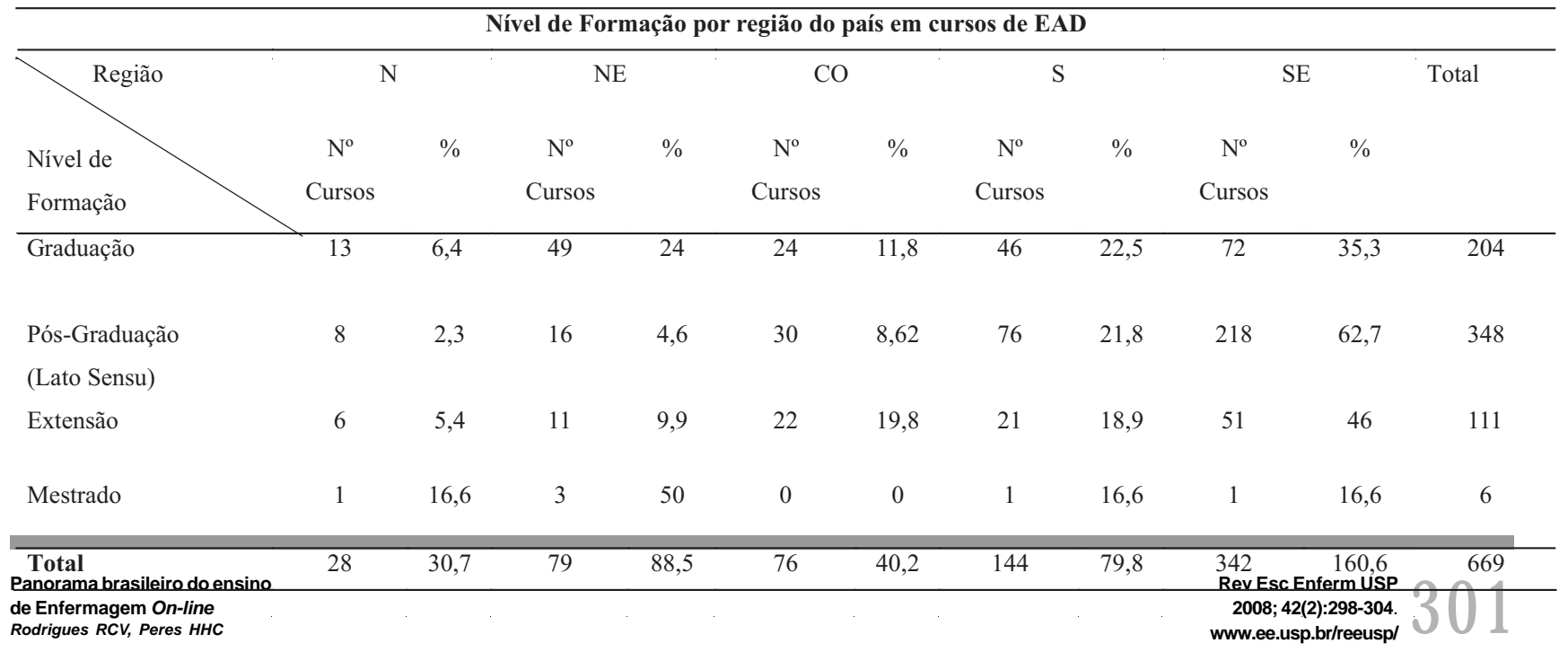


A educação on-line parte de pressupostos pedagógicos da aprendizagem colaborativa ou cooperativa onde é esperada e incentivada a participação do aluno, pois a troca de informações e experiências produzem mais conhecimento e promovem 0 aprendizado ${ }^{(18)}$.

A tabela 4 nos mostra um quadro geral dos cursos a distância distribuídos por área de concentração, região do Brasil e nível de formação. Nesta tabela podemos verificar que a área de concentração que mais oferece cursos a dis- tância é a área de humanidades nas cinco regiões brasileiras. Em segundo lugar temos a área de exatas que apresenta o maior número de cursos em todas as regiões exceto a região sudeste onde a área de biológicas prevalece.

$\mathrm{Na}$ área de humanidades a maioria dos cursos oferecidos é voltada à Educação e Administração. Na área de biológicas prevalecem os cursos voltados às Ciências Biológicas e na área de exatas os cursos voltados às áreas de Matemática e Informática.

Tabela 4 - Distribuição dos cursos superiores na modalidade EAD por áreas de concentração, nível de formação e regiões do Brasil - São Paulo - 2006

Cursos de EAD por Áreas de Concentração, Nível de formação e por Regiões Brasileiras

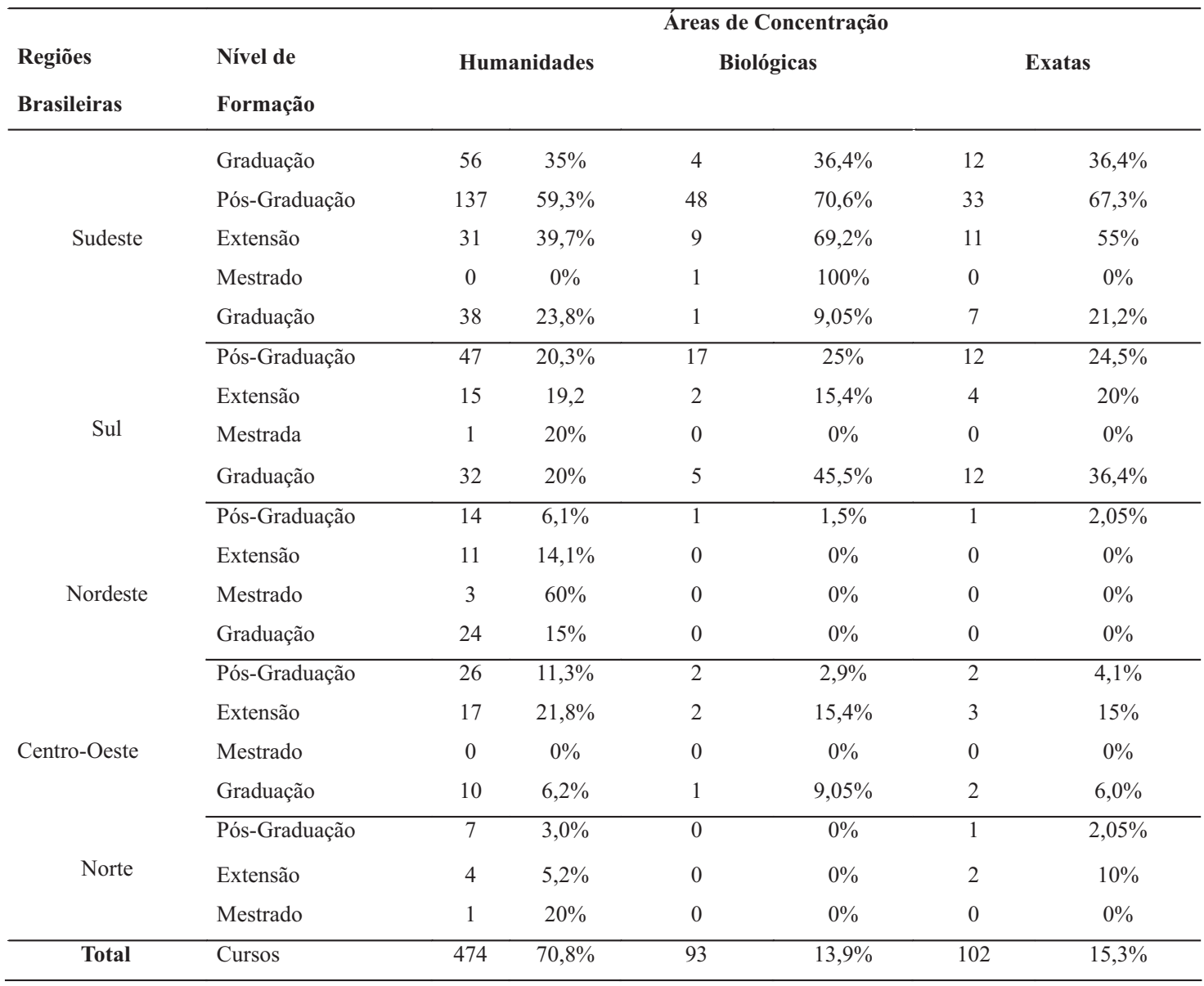

Todos os cursos oferecidos pelas IES foram catalogados em nosso estudo a fim de verificar e identificar se havia algum curso a distância oferecida especificamente para a Enfermagem. Constatamos que havia apenas dois cursos de pós-graduação e são eles:

- Enfermagem em Saúde M ental e

- Enfermagem em Nefrologia

A constatação da existência de apenas dois cursos de pós-graduação em EAD na Enfermagem demonstra a falta de adoção ao processo de modernização das técnicas de ensino e de adequação às mudanças que as novas tecnologias impactam no processo educacional.

Encontramos na literatura acadêmica vários trabaIhos direcionados à construção de sites voltados à educação continuada em Enfermagem com avaliações muito positivas mas que não possuem continuidade após sua defesa ou apresentação à comunidade ${ }^{(1,4)}$.

$\mathrm{Na}$ Internet também são escassos os portais, sites e grupos de discussão brasileiros voltados à profissão e que poderiam representar excelentesoportunidades de crescimento. 
A Enfermagem é considerada por muitos uma profissão essencialmente prática, porém, este fato não se opõe à utilização da EAD como forma ou meio para viabilizar a educação continuada através da realização de cursoslivres, de extensão e pós-graduação on-line.

0 espaço virtual permite reunir e integrar diversas mídias com finalidades diferentes possibilitando a criação de atividades variadas e multifacetadas. Podemos utilizar recursos diversos como áudio, vídeo e hipertextos para recriar a realidade oferecendo oportunidades de experimentação prática por parte do aluno sem que este coloque em risco a vida de um paciente real. 0 emprego de estudos de caso e simulações nos permite criar situações de trabalho idênticas à realidade para que 0 aluno possa treinar tomada de decisões, identificar problemas, prioridades, levantar hipóteses, selecionar informações, analisar contextos e buscar soluções.

Devemos considerar que a EAD apresenta características organizacionais que facilitam a adequação do Enfermeiro à sua estrutura educacional como a inexistência de horário e local fixos para estudo e a ausência da necessidade de deslocamento do aluno até uma instituição de ensino para freqüentar as aulas. Sabemos que muitos profissionais desta área trabalham em longos turnos de 12 horas e, a maioria das vezes, possuem mais de um vínculo empregatício. A carga de trabalho extensiva de 40 horas semanais associado aos deveres com a família e filhos induzem ao cansaço e estresse reduzindo de forma estanque o tempo livre necessário ao estudo e à atualização profissional|(19-20).

\section{REFERÊNCIAS}

1. Zem-Mascarenhas SH. Apenenf: ambiente web de apoio ao ensino de enfermagem. In: Anais do 9o Congresso Brasileiro de Informática em Saúde; 2004 nov. 7-10; Ribeirão Preto [evento na Internet]. São Paulo: UNIFESP; 2004 [citado 2007 jan. 2]. Disponível em: http://telemedicina.unifesp.br/pub/SBIS/CBIS2004/trabalhos/arquivos/247.pdf.

2. United Nations Educational Scientific and Cultural Organization (UNESCO). Information and communication technology in education: a curriculum for schools and programme of teacher development. Paris; 2002.

3. Marziale $\mathrm{MPH}$, Mendes IAC. A enfermagem brasileira na era da informação e do conhecimento. Rev Lat Am Enferm. 2005;13(5):607-8.

4. Silva SB, Cassiani SHB, Zem-Mascarenhas SH. A Internet e a enfermagem: construção de um site sobre administração de medicamentos. Rev Lat Am Enferm. 2001; 9(1): 116-22.

5. Kenski VM. Tecnologias e ensino presencial e a distância. São Paulo: Papirus; 2004.
Ressaltamos, ainda, que a informatização das instituições de saúde vem se tornando premente e faz-se necessário que o enfermeiro possua conhecimentos e habilidades que possibilitem o uso da tecnologia da informática como instrumento no seu campo de atuação, seja para comunicação, educação, gestão, pesquisa e assistência ${ }^{(21)}$.

Neste contexto a EAD pode representar uma modalidade de ensino adequada para a qualificação do profissional enfermeiro que necessita manter-se atualizado, mas que, por questões sociais, econômicas ou mesmo geográficas, não possui condições de freqüentar um curso regular.

\section{CONSIDERAÇÕES FINAIS}

Diante do exposto, consideramos que a inserção da enfermagem no panorama do ensino on-line brasileiro ainda é incipiente. É necessário que as IES adotem políticas de investimento na capacitação tecnológica docente e discente, bem como na implementação de infra-estrutura para o desenvolvimento de projetos de EAD estruturados em propostas pedagógicas que viabilizem a construção de competências, habilidades e conhecimento nas áreas de tecnologia da informação e de educação utilizando novas estratégias de ensino.

Dessa forma, 0 atual panorama de EAD em enfermagem poderá sofrer mudanças rumo a apropriação e a aplicação efetiva das novas tecnologias no processo de ensino - aprendizagem, caminhando para assegurar maior participação da enfermagem em um mundo mediado pela tecnologia no qual ensinar e aprender on-line se faz cada vez mais presente e necessário.

6. Peres HHC. 0 ser docente de enfermagem frente ao mundo da informática: um olhar na perspectiva da fenomenologia social [tese]. São Paulo: Escola de Enfermagem, Universidade de São Paulo; 2001.

7. Brasil. M inistério da Educação e Cultura. Lei n. 9.394, de 20 de dezembro de 1996. Estabelece as diretrizes e bases da educação nacional [legislação na Internet]. Brasília; 1996 [citado 2006 jul. 30]. Disponível em: http:// ww w6. senado.gov.br/ legislacao/ListaPublicacoes. action?id=102480.

8. Vianney J, Torres P, Silva E. A universidade virtual no Brasil: os números do ensino superior a distância no país em 2002. In: Anais do Seminário Internacional sobre Universidades Virtuais na América Latina e Caribe; 2003 fev. 13-14; Quito, Equador. Quito; 2003. p. 74-87.

9. Almeida MEB. Educação a distância na Internet: abordagens e contribuições dos ambientes digitais de aprendizagem. Educ Pesq. 2003;29(3):327-40.

10. Dabbagh N, Bannan-Ritland B. Online Learning: concepts, strategies and application. New Jersey: Prentice May; 2005. 
11. Santos EO. Ambientes virtuais de aprendizagem: por autorias livres, plurais e gratuitas. Rev FAEEBA Educ Contempor. 2002;11(18):425-35.

12. Brasil. M inistério da Educação e Cultura. Portaria n. 4.059, de 10 de dezembro de 2004. Substitui a portaria 2.253/ 01 que normatizava os procedimentos de autorização para oferta de disciplinas na modalidade nãopresencial em cursos de graduação reconhecidos. Diário Oficial da União, Brasília, 13 dez. 2004. Seção 1, p. 34.

13. Peres HHC, Leite MMJ. Informática no ensino de enfermagem. In: Kalinowski CE, coordenadora. Programa de atualização em enfermagem: saúde do adulto (PROENF). Porto Alegre: Artmed; 2006. p. 58-74.

14. Brasil. Ministério da Educação e Cultura [home page na Internet]. Brasília; 2006 [citado 2006 jul. 30]. Disponível em: http://portal.mec.gov.br.

15. Brasil. Ministério da Educação e Cultura. Instituto Nacional de Estudos e Pesquisas Educacionais Anísio Teixeira [home page na Internet]. Brasília; 2006 [citado 2006 jul. 30]. Disponível em: http://www.inep.gov.br/ default2.htm.
16. Associação Brasileira de Educação a Distância [home page na Internet]. São Paulo; 2006 [citado 2006 jul. 30]. Disponível em: http://www2.abed.org.br.

17. Associação Brasileira de Educação a Distância. Anuário brasileiro estatístico de educação aberta e a distância. São Paulo: Instituto Monitor; 2006.

18. Lévy P. Cibercultura. São Paulo: 34; 1999.

19. Bastos MAR, Guimarães EMP. Educação a distância na área de enfermagem: relato de uma experiência. Rev Lat Am Enferm. 2003;11(5):685-91.

20. Twomey A. Web-based teaching in nursing: lessons from de literature. Nurs Educ Today. 2004;24(6):452-58.

21. Dias DC, Cassiani SHB. Educação de Enfermagem sem distâncias: uma ruptura espaço/temporal. Rev Esc Enferm USP. 2004;38(4):467-74. 